\title{
A Mathematical Model of Divine Infinity
}

Prof. Eric Steinhart, Department of Philosophy, William Paterson University, Wayne NJ 07470. Email: <esteinhart1@nyc.rr.com>, <steinharte@wpunj.edu>.

Published in 2009 in Theology and Science 7 (3), 261 - 274.

ABSTRACT: Mathematics is obviously important in the sciences. And so it is likely to be equally important in any effort that aims to understand God in a scientifically significant way or that aims to clarify the relations between science and theology. The degree to which God has any perfection is absolutely infinite. We use contemporary mathematics to precisely define that absolute infinity. For any perfection, we use transfinite recursion to define an endlessly ascending series of degrees of that perfection. That series rises to an absolutely infinite degree of that perfection. God has that absolutely infinite degree. We focus on the perfections of knowledge, power, and benevolence. Our model of divine infinity thus builds a bridge between mathematics and theology.

KEYWORDS: God; mathematics; perfection; infinity; Cantor; transfinite recursion.

\section{Introduction}

All will agree that science makes extensive use of mathematics. At least in physics, scientific progress seems to go hand in hand with increasing formalization. More sophisticated physical theories are also more highly mathematical. And the correlation of progress with increasing formalization also appears sciences like chemistry and biology as well. Mathematics is obviously important in the sciences. And so it is likely to be equally important in any effort that aims to understand God in a scientifically significant way or that aims to clarify the relations between science and theology. Nevertheless, mathematics has seen little application in theology. There are few mathematical models of God.

Our goal is to show how contemporary mathematics can be used to model the notion of divine infinity. We are not doing natural theology; our project is to analyze the theological concept of God in light of the best available contemporary mathematics. To be God is to be maximally perfect (Morris, 1987). Maximal perfection is absolutely infinite. So, for any divine perfection $\mathrm{P}$, the degree to which God has $\mathrm{P}$ is absolutely infinite. For example, the knowledge, power, and benevolence of God are all absolutely infinite. We will provide a mathematical model of what it means to say that, for certain perfections, the degree to which God has those perfections is absolutely infinite. We will focus on the three main classical perfections of knowledge, power, and benevolence.

To model divine infinity, we need two background theories. The first background theory is mathematical. This is easy. We just use modern set theory. This theory is based on the work of Georg Cantor (Dauben, 1990). The second theory is theological. We need 
some background theory of God. This is hard - no theory of God will satisfy everybody. And we don't have the space to consider every possible theory. Our work here is based on what has been called classical theism. We are thus inspired by figures as diverse as Augustine (Drozdek, 1995), Gregory of Rimini (Thakkar, 2009), Leibniz, Royce, and Plantinga. And, of course, by Cantor himself. For Cantor, theology was a part of the inspiration for his mathematics (see Hallett, 1988: ch. 1; Dauben, 1977). By using classical theism, we do not mean to exclude other theologies. However, we cannot hope to build more than one bridge in one article. We hope that we will be able to link infinity with non-classical theisms in future work. Finally, before we start, we want to stress that we're not doing a historical survey (for such surveys, see Leblanc, 1993; Achtner, 2005).

Equipped with these background theories, we can begin. Section 2 introduces the modern Cantorian theory of infinity. Section 3 uses the Cantorian theory to model the infinite decimal expansion of $\pi$ and the infinite influence of a person. Section 4 introduces the concept of higher infinities and how transfinite recursion can be used to define divine perfections. The next three sections deal, respectively, with the knowledge, power, and goodness of God. Our conclusions are in Section 8.

\section{Introducing Infinity}

A long time ago, Aristotle introduced the concept of a potentially infinite series. A potential infinity is always coming into being; it is never wholly present. ${ }^{1}$ Suppose F is some type of event or entity (e.g. ticks of a clock, steps into space, cuts in a line, numbers). A series of Fs is potentially infinite if and only if that series is defined by some recursive procedure. A recursive procedure for defining a series of Fs has two rules. It has an Initial Rule that defines the initial F in the series. And it has a Successor Rule that shows how to extend any given series of Fs by defining the next $\mathrm{F}$ in terms of the previous Fs. A recursive procedure does not define any last F. For any previously defined Fs, the Successor Rule always defines another later F. To illustrate potential infinity, suppose Zeus aims to count through all the natural numbers. He produces the initial natural number 0 at some time. He then continues, saying 1, 2, 3, and so on. These are the successor numbers. Assuming that Zeus is immortal, he will always be able to say another number. There will always be another possible number for Zeus to count. Zeus will never reach the end.

Aristotle contrasted potential infinity with actual infinity. An actually infinite series is wholly present at some single moment of time. A series $\mathrm{S}$ is actually infinite at some time $t$ if and only if (1) the initial object of $S$ exists at $t$; and (2) for every object in $S$ at $t$, there is another successor object in $S$ at $t$. It is a completed or whole totality with infinitely many members. To illustrate an actually infinite series, suppose that Zeus has a perfect memory. As he counts through the numbers, he records each number in a mental list. As he counts, his mental list is a series of numbers that grows ever larger. If there is ever any time at which this list is actually infinite, then there is some time t such that (1) 0 is on Zeus's mental list at $t$ and (2) for every number $n$ on Zeus's list at $t$, the successor number $n+1$ is also on his list at $t$. Of course, this means that there is some time at which 
Zeus has counted through all the numbers. Most Aristotelians would deny that it is possible for there to be any such time. Since there is no greatest number, Zeus cannot make any actually infinite list of numbers. Most Aristotelians deny the reality of any actual infinities. ${ }^{2}$

After Aristotle, there was considerable interest in the actually infinite (Duhem, 1985: pt. 1). And while denial of the actual infinite was widespread, it was not universal. Augustine argued that God grasps the actual infinity of numbers in a single thought (City of God, bk. 12, ch. 18). Duns Scotus said that what is potentially infinite to us is actually infinite to God (A Treatise On God as First Principle, sec. 4.48). And it seems consistent with the notion of potential infinity to say that, for any finitely long interval of time, for any moment within that interval, there will be another later moment still within that interval. Surprisingly, this means that an agent whose creative power is unlimited can produce an actually infinite series of objects in any finite interval of time. On the basis of this reasoning, Gregory of Rimini argued that God can produce an actually infinite series of objects (Duhem, 1985: 109-119; Thakkar, 2009). ${ }^{3}$ For example, God can make an actual infinity of angels in a finite interval of time. God creates an initial angel in $1 / 2$ minute; God then creates every successor angel twice as fast; at 1 minute, God has created an actual infinity of angels. Suppose God gives these angels names. If God makes a mental list of the names of these angels as he creates them, then the mind of God contains an actually infinite list at 1 minute.

Astonishingly, Gregory's insights languished for nearly 600 years. However, during the 19th century, the success of the calculus suggested to many thinkers that space and time were actually infinitely divided (see Moore, 2001: ch. 8). Between any two moments in time, there is an interval containing an actual infinity of moments. Between any two points in space, there is a line segment containing an actual infinity of points. ${ }^{4}$ For example, consider a line segment whose length is 1 meter. It is stretched from 0 to 1 . There is a point halfway between 0 and 1 . It is the point $1 / 2$. Between $1 / 2$ and 1 , there lies the point $3 / 4$. Hence the line segment from 0 to 1 contains an infinite series of points: $0,1 / 2,3 / 4,7 / 8,15 / 16,31 / 32$, and so on. This series is not produced by any agent who chops up the line segment by performing successive acts of division in time. It is wholly present. By the end of the 19th century, Georg Cantor decisively breaks with Aristotle. Cantor argues that every potentially infinite series presupposes an actually infinite series (Hallett, 1988: sec. 1.2). Cantor's work begins the theory of transfinite numbers.

According to an early version of the Cantorian theory, numbers are defined by three rules (Hallett, 1988: 49). These are the Initial Rule; the Successor Rule; and the Limit Rule. We state these rules and then comment on them. They look like this:

0.1 Initial Rule. There exists an initial number 0 .

0.2 Successor Rule. For every number $\mathrm{n}$, there exists a successor number $\mathrm{n}+1$.

0.3 Limit Rule. For any endless series of numbers, there exists a limit number greater than every number in that series. 
The Initial Rule needs little comment. It just says 0 exists. Given 0, the Successor Rule defines a series of finite numbers. The successor of 0 is 1 ; the successor of 1 is 2 ; and so it goes. This series is not defined temporally. The rules say nothing about an agent who produces these numbers one after another in time. They simply say that the numbers exist. The series of finite numbers is endless. However, it is not endless in time. To say that the series of numbers is endless is to say only that for every member of the series, there exists a greater member. Since the series of finite numbers is endless, the Limit Rule says that there exists a limit number greater than every number in that series. Cantor gave the name $\omega$ to that first limit number. Since $\omega$ is greater than every number in the series of finite numbers, $\omega$ is not finite. More precisely, $\omega$ is the first transfinite number - the first number beyond the finite. The number $\omega$ is just the first transfinite number on a transfinitely long number line. Since $\omega$ is a number, it has a successor $\omega+1$. And $\omega+1$ is followed by $\omega+2$. Then $\omega+3, \omega+4$, and so on. So the next limit number is $\omega+\omega$. Followed by $\omega+\omega+1 \ldots$.

Although the formal structure of Cantor's theory of actual infinities is almost universally accepted, some thinkers remain skeptical about the real existence of actual infinities. We offer an indispensability argument for actual physical infinities: ${ }^{5}$ (1) we ought to believe in something if it is indispensable to our best science; (2) actual physical infinities are indispensable to our best physical theories; therefore (3) we ought to believe in actual physical infinities. And, by analogous arguments, we ought to believe in the existence in at least all the actual mathematical infinities needed to analyze the formal structure of those indispensable actual physical infinities. Byl (2007) uses the indispensability of infinities in physics and mathematics to argue for theism. He argues that the best explanation for the existence of actual physical and mathematical infinities is the existence of an actually infinite God. Indeed, Byl argues that if there were no actual infinities, we would be deprived of some of our best reasons for thinking that God exists.

\section{Infinite Sequences}

A natural way to model an infinite object is to define an infinite series of increasingly accurate approximations to that object. Just as $\omega$ is the limit of the series of finite numbers, so the infinite object is the limit of the series of increasingly accurate approximations. For example, consider the number $\pi$. The decimal expansion of $\pi$ is infinitely long. So the natural way to define the decimal expansion of $\pi$ is to define an infinite series of increasingly accurate approximations to that expansion. Greater accuracy goes hand in hand with greater length. Formally, for any number $n$, let $D(\pi, n)$ be the decimal expansion of $\pi$ out to $n$ digits. The decimal expansion is just a list of digits (we ignore the decimal point). So $D(\pi, 0)$ is 3 . Then $D(\pi, 1)$ is 31 . Then $D(\pi, 2)$ is 314 . Then $\mathrm{D}(\pi, 3)$ is 3141 . And so it goes. We can write all this formally using Cantor's rules: 
1.1 Initial Rule. For the initial number 0 , the initial expansion $\mathrm{D}(\pi, 0)$ is 3 .

1.2 Successor Rule. For every successor number $n+1$, the successor expansion $D(\pi, n+1)$ is defined by taking $\mathrm{D}(\pi, \mathrm{n})$ and adding the next digit of $\pi$. Each $\mathrm{D}(\pi, \mathrm{n}+1)$ is more accurate than its predecessor and is closer to $\mathrm{D}(\pi)$ itself.

1.3 Limit Rule. For the infinite number $\omega$, the infinite expansion $\mathrm{D}(\pi, \omega)$ is the limit of the series of $\mathrm{D}(\pi, \mathrm{n})$ for every finite $\mathrm{n}$. The series of finite expansions converges to the infinite expansion. And $\mathrm{D}(\pi, \omega)$ is the fully accurate decimal expansion of $\pi$. We therefore identify $\mathrm{D}(\pi)$ with $\mathrm{D}(\pi, \omega)$.

We often use sets to model various features of things. For example, consider strength. How can we define the strength of a person? One plausible way is to identify the strength of a person with the set of all the objects that can be lifted by that person. So the strength of Bob is the set of all objects that can be lifted by Bob. To have more strength is to be able to lift a more inclusive set of objects. If Bob is stronger than Carl, then the set of things Bob can lift is more inclusive than the set of things that Carl can lift.

As another example, consider influence. To put it crudely, the influence of a person $\mathrm{x}$ is the set of people who do what $x$ tells them to do. The influence of a person can spread out in degrees. Consider the influence of some person Richard. The zeroth degree of Richard's influence is just Richard. Richard now tells some people both to pat their heads and to tell others to do the same (that is, to tell others both to pat their heads and to tell others...). The first degree of Richard's influence is Richard plus all the people who do what Richard tells them to do. The second degree of Richard's influence includes all the people in the previous degrees plus all the people that they influence. And so it goes. For an arbitrary person $\mathrm{x}$, we define degrees of influence of $\mathrm{x}$ like this:

2.1 Initial Rule. For the initial number 0 , the initial degree of influence of $\mathrm{x}$ is $\operatorname{In}(\mathrm{x}, 0)$. This initial degree includes just $\mathrm{x}$ himself or herself.

2.2 Successor Rule. For every successor number $n+1$, the successor degree of influence of $x$ is $\operatorname{In}(x, n+1)$. The successor degree $\operatorname{In}(x, n+1)$ is the previous degree $\operatorname{In}(x, n)$ plus all the people influenced by people in $\operatorname{In}(\mathrm{x}, \mathrm{n})$.

2.3 Limit Rule. For the infinite number $\omega$, the limit degree of influence of $\mathrm{x}$ is $\operatorname{In}(\mathrm{x}, \omega)$. The limit degree $\operatorname{In}(\mathrm{x}, \omega)$ includes all people in all lesser degrees. It includes every person in every degree $\operatorname{In}(\mathrm{x}, \mathrm{n})$ for any finite $\mathrm{n}$.

What does it mean to say that the influence of a person is infinite? It means that the sequence of their degrees of influence is always growing. The next degree is always more inclusive than the previous degree. For example, Richard influences some people; they influence more people; they influence even more people; and so it goes. To say that the influence of Richard is infinite is to say that every next degree of influence is a bigger set of people. The limit degree includes all these people. For any person $x, \operatorname{let} \operatorname{In}(\mathrm{x})$ be the influence of $x$. For any person $x$, if the influence of $x$ is infinite, then $\operatorname{In}(x)$ is equal to 
$\operatorname{In}(\mathrm{x}, \omega)$. For example, if the influence of Richard is infinite, then In(Richard) is In(Richard, $\omega)$. We now have a conception of infinite influence that is both mathematically precise and that is generalizable to higher degrees of infinity.

\section{Into the Transfinite}

One of the most impressive results of the modern theory of infinity is that $\omega$ is not the biggest infinite number. The number line extends endlessly far beyond $\omega$. It extends far out into the transfinite. The transfinite number line (the Long Line) is defined in set theory. Set theory is highly technical and we won't go into any detail here. Here we provide only an introductory and very high-level overview.

The most basic version of set theory is known as Zermelo - Fraenkel - Choice set theory (ZFC). Many excellent introductions to ZFC are widely available (e.g. Hamilton, 1982; Devlin, 1991). ZFC can be used to define the most basic version of the Long Line. But $\mathrm{ZFC}$ is not the biggest theory of sets. It defines a tiny universe of sets and a short number line. It is logically possible to extend $\mathrm{ZFC}$. This means that $\mathrm{ZFC}$ does not define any absolute infinities. To be absolutely infinite is to be infinite in a way that is logically maximal. Since we're interested in an absolutely infinite object (God), we want to use that number line than which no longer is logically possible. So we need to extend ZFC, and its short line, as far as it can be extended without contradiction. ZFC is extended by adding special existence axioms, known as large cardinal axioms (Drake, 1984). These axioms assert the existence of transfinite numbers that are extremely large.

When we add large cardinal axioms to ZFC, we get a new set theory. Let ZFC* be ZFC plus all consistent large cardinal axioms. Since $\mathrm{ZFC}^{*}$ includes all consistent large cardinal axioms, any extension of $\mathrm{ZFC}^{*}$ is inconsistent. $\mathrm{ZFC} *$ is the logically maximal set theory. The number line determined by ZFC* is the logically maximal number line. It is the Long Line. Since the length of the Long Line is logically maximal, it is absolutely infinitely long. There are three kinds of numbers on the Long Line. The first kind includes only the initial number 0 . The second kind includes every successor number. Every successor number has the form $n+1$ where $n$ is some number on the Long Line. For instance, 1 is a successor number; but so is $\omega+1$. The third kind includes every limit number. Every limit number is defined as the upper bound of some infinite series of numbers. For example, $\omega$ is a limit number. But there are greater limit numbers.

We use the Long Line to define a series of increasingly accurate approximations to divine perfection. For any number $\mathrm{n}$ on the Long Line, the $\mathrm{n}$-th approximation is the $\mathrm{n}$-th degree of divine perfection. Since the Long Line is absolutely infinitely long, the series of degrees of any perfection rises to an absolutely infinite degree of that perfection. When we use the Long Line to define these degrees, we are going beyond ordinary recursion (which just uses Initial and Successor Rules). We are defining the degrees by transfinite recursion. ${ }^{6}$ A definition by transfinite recursion involves a rule for each kind of number on the Long Line. So it involves an Initial Rule, a Successor Rule, and a Limit 
Rule. To reach the absolute infinite, we also add a Final Rule. For any perfection $\mathrm{P}$, the definition of the degrees of $\mathrm{P}$ by transfinite recursion has this form:

3.1 Initial Rule. For the initial ordinal 0, there exists an initial degree of the divine perfection $\mathrm{P}$. This is $\mathrm{P}(\mathrm{God}, 0)$. Following our earlier examples, $\mathrm{P}(\mathrm{God}, 0)$ is some initial set of objects (e.g., those that are least relative to the perfection).

3.2 Successor Rule. For every successor number $n+1$ on the Long Line, there exists a successor degree of the perfection $\mathrm{P}$. This is $\mathrm{P}(\mathrm{God}, \mathrm{n}+1)$. Following our earlier examples, $\mathrm{P}(\mathrm{God}, \mathrm{n}+1)$ is a set of objects. And just as the number $\mathrm{n}+1$ is defined in terms of $n$, so $\mathrm{P}(\mathrm{God}, \mathrm{n}+1)$ is defined in terms of $\mathrm{P}(\mathrm{God}, \mathrm{n})$. Each next degree of $\mathrm{P}$ is an extension or amplification of the previous degree.

3.3 Limit Rule. For every limit number L on the Long Line, there exists a limit degree of the perfection $\mathrm{P}$. This is $\mathrm{P}(\mathrm{God}, \mathrm{L})$. Following our earlier examples, $\mathrm{P}(\mathrm{God}, \mathrm{L})$ is a set of objects. And just as the number $\mathrm{L}$ is defined in terms of all the numbers less than $\mathrm{L}$, so $\mathrm{P}(\mathrm{God}, \mathrm{L})$ is defined in terms of $\mathrm{P}(\mathrm{God}, \mathrm{k})$ for all $\mathrm{k}$ less than $\mathrm{L}$. Each limit degree of $\mathrm{P}$ is defined as the union of the entire progression of lesser degrees of $\mathrm{P}$.

3.4 Final Rule. There is a maximal degree of the perfection $\mathrm{P}$. Formally, $\mathrm{P}(\mathrm{God})$ is defined in terms of $\mathrm{P}(\mathrm{God}, \mathrm{k})$ for every number $\mathrm{k}$ on the Long Line. Since $\mathrm{P}(\mathrm{God})$ is defined in terms of every number on the Long Line, it is absolutely infinite. $\mathrm{P}(\mathrm{God})$ is a collection of objects. However, this collection is not a set. For those who are familiar with the technical details, $\mathrm{P}(\mathrm{God})$ is a proper class.

\section{The Knowledge of God}

The first main classical perfection of God is knowledge. The knowledge of God is absolutely infinite. We want to define this mathematically. To say that God has knowledge implies that God has a mind and that the mind of God contains ideas. An idea in the mind of God is a mental representation of some possibly existing thing. It is an exact description of that thing. Presumably, God can think about any possible thing. God can think about numbers, sets, protons, horses, universes, and so on. If this is right, then God has ideas of numbers, of sets, of physical things, of universes, and so on. Following Leibniz (Theodicy, secs. 414 - 417), we say that God's idea of a universe is a complete and perfectly accurate description of that entire universe at every moment of its history. ${ }^{7}$

We don't have to worry too much about the details of what it means to be a divine idea. Our main concern is with the organization of the ideas in the divine mind. Clearly, there are some divine ideas. God has some knowledge. And, equally clearly, some of these divine ideas are more complex than others. More complex divine ideas are composed of simpler divine ideas. Complex divine ideas have internal structure. For instance, there is some sense in which the idea of a hydrogen atom is composed of the idea of a proton and the idea of an electron. The idea of the hydrogen atom is more complex than the ideas of its parts. As another example, consider natural numbers. Many mathematicians say that every natural number is the set of all lesser natural numbers. So 3 is the set $\{0,1,2\}$. It 
seems reasonable to say that the idea of a set is somehow composed of the ideas of its members. If this is right, then there is some sense in which the idea of the number 3 is composed of the ideas of the numbers 0,1 , and 2 . Thus the idea of every greater natural number is more complex than the ideas of all the lesser natural numbers. As another example, the idea of a possible universe is composed of the ideas of all the things in that universe. The idea of that universe is more complex than the idea of each thing that it contains.

Any mathematical model is based on some ultimate assumptions. These are typically expressed as axioms. Our model of divine knowledge is based on five axioms. The first axiom says that some divine ideas are the simplest divine ideas. They aren't composed of any other divine ideas. For example, quarks are said to be simple physical things. If this is right, then the idea of a quark is among the simplest divine ideas. Likewise for the idea of an electron. As another example, the number 0 isn't composed of any other numbers; it's the simplest number. So it's fair to say that the idea of the number 0 is a simple idea. And since the empty set doesn't contain any members, it's fair to say that the idea of the empty set is a simple idea (indeed, 0 is typically identified with the empty set).

The first axiom implies that there is a lowest level of mental complexity in the divine mind. The simplest ideas are on the lowest level of the divine mind - the bottom shelf in the divine mental library. The bottom level is level 0 . The least degree of divine knowledge includes every idea in level 0 . Formally, $\mathrm{K}(\mathrm{God}, 0)$ is the 0 -th degree of divine knowledge. $\mathrm{K}(\mathrm{God}, 0)$ is a set of ideas in the divine mind. God knows every idea in that set.

The second axiom says that simpler divine ideas are combined in all possible ways to make more complex divine ideas. Since God is all-knowing, God cannot be ignorant of any possible combinations. The second axiom implies that there are levels of the divine mind above the bottom level. More complex ideas are on higher levels. The degrees of divine knowledge correspond to the complexity levels of divine ideas. Certainly, more intelligence is required to know more complex ideas. Since protons are made of many quarks, it takes more intelligence to understand the idea of a proton than to understand the idea of a quark. And, if every natural number is the set of all lesser natural numbers, then it takes more intelligence to understand 5 than it takes to understand 4.

Accordingly, the first degree of divine knowledge is $\mathrm{K}(\mathrm{God}, 1)$. This degree contains all the ideas formed out of simple ideas. The second degree is $\mathrm{K}(\mathrm{God}, 2)$. An idea on this second degree can be formed by composing just ideas in degree 1 or by composing an idea in degree 1 with an idea in degree 0 . This degree contains any combination of ideas that involves at least one idea from degree 1. For every degree of divine knowledge, there is a successor degree. For any $n$-th degree, there is an $(n+1)$-th degree. Generally, the $(n+1)$-th degree of divine knowledge $K(\mathrm{God}, \mathrm{n}+1)$ contains every combination of less complex ideas that involves at least one idea from the $n$-th degree $K(\operatorname{God}, n)$.

The third axiom says that for any endlessly increasing series of degrees of knowledge in the divine mind, there is a limit degree that includes all those levels. The first limit 
degree is the $\omega$-th degree of divine knowledge. It is $\mathrm{K}(\mathrm{God}, \omega)$. Limit degrees don't add any new ideas. They merely gather together or accumulate the ideas on all lesser degrees. So $\mathrm{K}(\mathrm{God}, \omega)$ includes every finitely complex idea in the divine mind. For example, $\mathrm{K}(\mathrm{God}, \omega)$ includes God's knowledge of every finitely complex physical thing. It includes God's knowledge of every finite number, or of every finitely complex set. But $\mathrm{K}(\mathrm{God}, \omega)$ does not include any infinitely complex ideas. They will appear in the next degree.

The fourth axiom says that some divine ideas are infinitely complex. God has an idea for every possible universe; some of those are infinitely complex; so God has some infinitely complex ideas. Consider an irrational number like $\pi$. As we've already discussed, the decimal expansion of $\pi$ is infinitely long (3.141592654...). Surely God knows the decimal expansion of $\pi$. The divine idea of the decimal expansion of $\pi$ is an infinitely complex idea. Hence the mind of God contains an infinitely complex idea. Likewise, Augustine says that God knows the entire infinite sequence of natural numbers as a single entity (City of God, bk. 12, ch. 18). To use modern terminology, God knows the set of all natural numbers. This set is $\omega$. The divine idea of $\omega$ is an infinitely complex idea. Since the idea of $\omega$ is not finitely complex, it does not appear in $K(\mathrm{God}, \omega)$. It first appears on the next degree. This is the successor degree $\mathrm{K}(\mathrm{God}, \omega+1)$. Finally, the fifth axiom says that for every possible (consistently definable) mathematical object, God has an idea of that object. God is not ignorant of any possible mathematical object. Cantor used this principle to justify the existence of infinite numbers and sets (Dauben, 1977).

We've given five axioms for divine knowledge. We can use them to associate every kind of number on the Long Line with a degree of divine knowledge. We can use them to define the knowledge of God by transfinite recursion. Since there are three kinds of numbers on the Long Line (initial, successor, and limit), there are three rules for divine knowledge. We add a fourth rule (a final rule) to get to the absolute infinite. The rules are:

4.1 Initial Rule. The least degree of divine knowledge is $\mathrm{K}(\mathrm{God}, 0)$. This degree contains all simple divine ideas. For every idea $\mathrm{x}$ in $\mathrm{K}(\mathrm{God}, 0)$, God knows $\mathrm{x}$.

4.2 Successor Rule. For every successor number $n+1$ on the Long Line, the $(n+1)$-th degree of divine knowledge is $\mathrm{K}(\mathrm{God}, \mathrm{n}+1)$. This degree contains every possible combination of less complex ideas involving at least one idea from $\mathrm{K}(\mathrm{God}, \mathrm{n})$. So, the next degree of divine knowledge is the largest possible expansion of all the previous degrees. Thus the mind of God increases in knowledge in a maximal way.

4.3 Limit Rule. For every limit number L on the Long Line, the L-th degree of divine knowledge is $\mathrm{K}(\mathrm{God}, \mathrm{L})$. A limit degree doesn't add any new ideas. It merely gathers together or accumulates all the ideas in all lower degrees. Hence the degree $\mathrm{K}(\mathrm{God}, \mathrm{L})$ includes every idea in every degree $\mathrm{k}$ for $\mathrm{k}$ less than $\mathrm{L}$. Consider the lease infinite degree of divine knowledge $\mathrm{K}(\mathrm{God}, \omega)$. It includes every idea in $\mathrm{K}(\mathrm{God}, 0)$ plus every idea in $\mathrm{K}(\mathrm{God}, 1)$ plus every idea in . . . K $(\mathrm{God}, \mathrm{n})$. . . and so on. 
4.4 Final Rule. The final degree of divine knowledge is $\mathrm{K}(\mathrm{God})$. This degree contains all divine ideas on all lower levels. It is the total or maximal accumulation of divine ideas. Formally, for any number $\mathrm{k}$ on the Long Line, for any idea $\mathrm{x}$, if $\mathrm{x}$ is in some degree $\mathrm{K}(\mathrm{God}, \mathrm{k})$, then $\mathrm{x}$ is in $\mathrm{K}(\mathrm{God})$. The final degree of divine knowledge is identical with the total content of the divine mind. It is the knowledge of God.

\section{The Power of God}

The second main classical perfection of God is power. God is absolutely infinitely powerful. Divine power is creative power (Morris, 1991). It is the power to create some object. We use transfinite recursion to define this power. The $\mathrm{n}$-th degree of divine power is $\mathrm{P}(\mathrm{God}, \mathrm{n})$. How do we define the degrees of divine power? Certainly, the power of God parallels the knowledge of God. If God has an idea, then God has the power to create something that is a model of that idea. Equivalently, if God has a description, then God has the power to create something that fits or satisfies that description. So we might say that for every number $\mathrm{n}$ on the logically maximal number line, $\mathrm{P}(\mathrm{God}, \mathrm{n})$ is identical to $\mathrm{K}(\mathrm{God}, \mathrm{n})$. Of course, to say that God can create an object does not imply that God does create it. It merely implies that God has the ability or capacity (the power) to create it.

We now come to a perplexing question: does God create mathematical objects? We said that God has ideas of these objects - for every number, God has an idea of that number. It would be fascinating to go into this question; but it would take up too much space. ${ }^{8}$ So we'll just be content with saying that mathematical objects are ideas in the mind of God. We'll focus our attention on physical things. Physical things exist in universes. Every possible physical thing either is a part of some possible universe or is identical with some possible universe. So we're focusing on the power of God to create universes. To create a possible universe is to actualize that universe. It is to produce an actual universe that corresponds to the possibility. God has an idea of every possible universe. The idea is in some degree of divine knowledge. We thus identify the $n$-th degree of divine power with the set of possible universes on the $\mathrm{n}$-th degree of divine knowledge. Formally, for any $\mathrm{n}$ on the Long Line, $\mathrm{P}(\mathrm{God}, \mathrm{n})$ is the set of all $\mathrm{x}$ such that $\mathrm{x}$ is a possible universe in $\mathrm{K}(\mathrm{God}, \mathrm{n})$. The power of God is $\mathrm{P}(\mathrm{God})$. It is the union of $\mathrm{P}(\mathrm{God}, \mathrm{n})$ for all $\mathrm{n}$ on the Long Line.

\section{The Benevolence of God}

The third main classical perfection of God is benevolence. Benevolence is active. It is the power of God directed in an active way towards the realization of the best. Divine benevolence is divine actualization - it creates value by changing the merely possible into the actual. To define divine benevolence, we start with a system of axioms. These axioms determine the four rules in a definition by transfinite recursion. 
We give eight axioms for divine benevolence. Clearly, God has some ethical obligations. The first axiom for divine benevolence says that God does what God is ethically obligated to do. The second axiom comes from Leibniz: every universe in the mind of God has some ethical value (Theodicy, secs. $414-417$ ). The third axiom is vaguely utilitarian: the value of any universe corresponds to the quantity and quality of life in that universe. Sterile universes have no value. Universes with the least amount of life have the least value. Universes with more life have more value; they are better universes.

The fourth axiom allows us to define an initial rule for divine benevolence. The fourth axiom says that God is ethically obligated to maximize the value of creation. It follows from this that God is ethically obligated to create some universe; otherwise, the value of creation would be zero, which is not maximal. It also follows from this that God is ethically obligated to start by actualizing every least valuable universe. For if God does not start by actualizing all of these, then God will have failed to actualize some universes that contain some value; but then the value of creation would not be maximal.

The fifth and sixth axioms allow us to define a successor rule for divine benevolence. The fifth axiom is that, for every universe, there is at least one way to improve it (Reichenbach, 1979; Fales, 1994). Any way to improve a universe defines a better version of that universe. For any universe $\mathrm{x}$, and for any way to improve $\mathrm{x}$, there is another universe $y$ that is improved in that way. The sixth axiom is that, for any universe, if God actualizes that universe, then God is ethically obligated to actualize every improvement of that universe (Forrest, 1981; Coughlan, 1978).

The seventh and eighth axioms allow us to define a limit rule for divine benevolence. The seventh axiom involves the notion of an ethical progression of universes. An ethical progression is a sequence of universes in which every next universe in that sequence is an improvement of the previous universe. The seventh axiom says that for every ethical progression, there is at least one way to improve that entire ethical progression. To say that a universe $\mathrm{x}$ is an improvement of an entire ethical progression is to say that $\mathrm{x}$ is better than every universe in that progression. The eighth axiom says that for every ethical progression, if God actualizes that progression (by actualizing every universe in it), then God is ethically obligated to actualize every improvement of that progression.

According to these axioms, God actualizes a plurality of universes. God actualizes a multiverse (Kraay, 20XX). Within the framework of process theology, Edwards (2000) has also argued that God makes a multiverse. We use transfinite recursion to formally define this multiverse. For any $\mathrm{n}$ on the Long Line, the $\mathrm{n}$-th degree of divine benevolence is $\operatorname{Act}(\mathrm{God}, \mathrm{n})$. Each degree of divine benevolence is a set of possible universes. God actualizes every universe in every degree of divine benevolence. For any $n$ on the Long Line, and for any $\mathrm{x}$ in Act(God, n), God has the power to actualize $\mathrm{x}$ and the benevolence of God directs god to actualize x. The rules for divine benevolence look like this:

5.1 Initial Rule. The initial degree of divine benevolence actualizes every least valuable universe. Thus $\operatorname{Act}(\mathrm{God}, 0)$ is the set of all least valuable universes. 
5.2 Successor Rule. For any universe $\mathrm{x}$, if God actualizes $\mathrm{x}$, then God actualizes every improvement of $x$. More formally, for every successor number $n+1$ on the Long Line, for every universe $x$, if $x$ is in $\operatorname{Act}(\operatorname{God}, n)$, then for every $y$, if $y$ is an improvement of $\mathrm{x}$, then $\mathrm{y}$ is in $\operatorname{Act}(\operatorname{God}, \mathrm{n}+1)$.

5.3 Limit Rule. For every endless ethical progression of universes $f$, if God actualizes every universe in $f$, then God actualizes every improvement of $f$. More formally, for every limit number L on the Long Line, for every ethical progression defined on L, if God actualizes that progression, then for every universe $\mathrm{y}$, if $\mathrm{y}$ is an improvement of that progression, then $y$ is in $\operatorname{Act}(\mathrm{God}, \mathrm{L})$.

5.4 Final Rule. There is a maximal degree of divine benevolence. Formally, Act(God) is the union of all Act(God, $\mathrm{k})$ for all $\mathrm{k}$ on the Long Line. Act(God) is the Best. For every possible universe $\mathrm{x}$ in Act(God), God actualizes $\mathrm{x}$.

\section{Conclusion}

Our project here has been to use contemporary mathematics to model the absolutely infinite perfection of God. We modeled the three classical perfections: the knowledge, power, and benevolence of God. We explained what it means, for each perfection, for God to have that perfection in an absolutely infinite way. And we did this using the best available contemporary mathematics. Of course, objections can be raised against our project. No doubt the most serious objection to our model challenges the very idea of using mathematics of any kind to model the infinity of God. This objection can be raised from both the mathematical and the theological sides of our project.

On the mathematical side, the challenge to our project can be raised with formal precision: within the theory of infinity based on standard set theory, there is no way to decide the cardinality of the continuum. Indeed, there is a long list of similar undecidable propositions concerning mathematical infinities (Devlin, 1991: ch. 6.1). If mathematical rationality is not able to answer its own purely formal questions, then surely it is not adequate for the analysis of divine infinity! This challenge is both warranted and salutary. The necessary self-limitations of mathematical rationality compel us to be humble. It's a good thing to be reminded that reason has intrinsic limits. Nevertheless, no one would argue that we should stop using mathematics. It is a useful tool, especially in the sciences. We should apply it in theology as far as we can, and no further.

On the theological side, the challenge to our project is perhaps concerned more with content than with form. Divine infinity is the unsurpassable richness of concrete life; it is not the sterile orderliness of mathematical abstraction. Accordingly, even if mathematical rationality were fully adequate to solve its own problems, it would not be adequate in theology. An excellent reply was given by Josiah Royce. Royce (1899) was among the first to apply the new Cantorian theory of the infinite to theology. Speaking of the divine life, Royce writes (and the italics are his): 
[I]t is easy, as we have seen, to make light of mere numbers because they are so formal, and because one wearies of mathematics. But our present case is simply this: Of course the numbers, taken in abstract divorce from life, are mere forms. But if in the bare skeleton of selfhood, if in the dry bones of that museum of mere orderliness, the arithmetical series, - if, even here, we find such an endless wealth of relatively unique results of each new act of reflection, in case that act is taken in synthesis with the foregoing acts, - what may not be, what must be, the wealth of meaning involved in a reflective series whose basis is a concrete life, whose reflections give this life at each stage new insight into itself, and whose syntheses with all foregoing acts of reflection are themselves, if temporally viewed, as it were, new acts in the drama of this life? (Royce, 1899: 580) 


\section{Notes}

${ }^{1}$ It has often been argued that there is no middle ground between (1) the strictly finite and (2) the actual infinite. Hence Aristotle's notion of potential infinity is incoherent. See Umphrey, 2002: 128-130. See also Tiles, 1989, especially ch. 1.

${ }^{2}$ It is not entirely clear that an Aristotelian must deny the existence of actual infinities. After all, Aristotelians say the universe has no beginning; hence there have actually been infinitely many days before today. See Moore, 2001: ch. 2.5.

${ }^{3}$ Gregory of Rimini (c. 1300 - 1358) affirms that God can produce actual infinities. And Gregory even proposes solutions to the apparent part-whole paradoxes of the infinite. He anticipates Bolzano. See Duhem, 1985: 109-119; Moore, 2001:53; Thakkar, 2009. Thakkar cites Gregory of Rimini (1979-87, III 443:3-12).

${ }^{4}$ According to Weyl, if physical space is not continuous, then the Pythagorean Theorem does not hold in physical space. Yet it does hold. See Weyl, 1949: 43.

${ }^{5}$ Our indispensability argument for actual physical infinities parallels the Quine-Putnam indispensability argument for abstract mathematical objects. See Steiner (1998) and Colyvan (2001). We note that Hartry Field denies the existence of any abstract objects. Yet even he affirms that actual infinities are indispensable in physics (Field, 1980).

${ }^{6}$ On the one hand, a definition by recursion has two rules: an initial rule and a successor rule. It defines a potential infinity. On the other hand, a definition by transfinite recursion has at least three rules. It at least adds a limit rule to the initial and successor rules. It may also add a final rule. Transfinite recursion defines actual infinities.

${ }^{7}$ Many Leibnizian ideas concerning God and possible universes have been taken up, in various ways, in contemporary analytic philosophy of religion. For example, see Plantinga, 1974. We cannot go into further detail here.

${ }^{8}$ Plantinga (1980: 142-143) says that God does not create mathematical objects. But Menzel (1987) says that God does create them. We won't enter this debate here. 


\section{References}

Achtner, W. (2005) Infinity in science and religion. Neue Zeitschrift fur Systematische Theologie und Religionsphilosophie 47, 392-411.

Byl, J. (2007) Matter, mathematics, and God. Theology and Science 5 (1), 73-86.

Colyvan, M. (2001) The Indispensability of Mathematics. New York: Oxford University Press.

Coughlan, M. (1987) Must God create only the best possible world? Sophia 26 (2), 1519.

Dauben, J. W. (1977) Georg Cantor and Pope Leo XIII: Mathematics, theology, and the infinite. Journal of the History of Ideas 38 (1), 85-108.

Dauben, J. W. (1990) Georg Cantor: His Mathematics and Philosophy of the Infinite. Princeton, NJ: Princeton University Press.

Devlin, K. (1991) The Joy of Sets: Fundamentals of Contemporary Set Theory. New York: Springer-Verlag.

Drake, F. (1974) Set Theory: An Introduction to Large Cardinals. New York: American Elsevier.

Drozdek, A. (1995) Beyond infinity: Augustine and Cantor. Laval Theologique et Philosophique 51 (1), 127-140.

Duhem, P. (1985) Medieval Cosmology: Theories of Infinity, Place, Time, Void, and the Plurality of Worlds. Ed. \& trans. R. Ariew. Chicago: University of Chicago Press.

Edwards, R. (2000) How process theology can affirm creation ex nihilo. Process Studies $29(1), 77-96$.

Fales, E. (1994) Divine freedom and the choice of a world. International Journal for the Philosophy of Religion 35, 65-88.

Forrest, P. (1981) The problem of evil: Two neglected defenses. Sophia 20 (1), 49-54.

Gregory of Rimini (1979-87) Lectura super primum et secundum Sententiarum. Seven volumes. Ed. A. D. Trapp, V. Marcolino, et al. New York: Walter de Gruyter.

Hallett, M. (1988) Cantorian Set Theory and Limitation of Size. New York: Oxford University Press. 
Kraay, K. (20XX) Theism, possible worlds, and the multiverse. Forthcoming in Philosophical Studies. On line DOI <10.1007/s11098-008-9289-y>.

Menzel, C. (1987) Theism, platonism, and the metaphysics of mathematics. Faith and Philosophy 4 (4), $365-382$.

Moore, A. W. (2001) The Infinite. Second Edition. New York: Routledge.

Morris, T. (1987) Perfect being theology. Nous 21 (1), 19-30.

Morris, T. (1991) A modern discussion of divine omnipotence. In B. Davies (ed.) (2000) Philosophy of Religion. New York: Oxford University Press, 402-414.

Plantinga, A. (1974) The Nature of Necessity. New York: Oxford University Press.

Plantinga, A. (1980) Does God Have a Nature? Milwaukee, WI: Marquette University Press.

Reichenbach, B. (1979) Must God create the best possible world? International Philosophical Quarterly 19 (2), 203-212.

Royce, J. (1899/1927) The World and the Individual. First Series. Supplementary Essay. New York: The Macmillan Company.

Steiner, M. (1998) The Applicability of Mathematics as a Philosophical Problem. Cambridge, MA: Harvard University Press.

Thakkar, M. (2009) Mathematics in fourteenth-century theology. In J. Stedall and E. Robson (eds.), Oxford Handbook of the History of Mathematics. New York: Oxford University Press, 619-38.

Tiles, M. (1989) The Philosophy of Set Theory. Mineola, NY: Dover Books.

Umphrey, S. (2002) Complexity and Analysis. Lanham, MD: Lexingon Books.

Weyl, H. (1949) Philosophy of Mathematics and Natural Sciences. Trans. O. Helmer. Princeton, NJ: Princeton University Press. 